\title{
Saudação a Sebastian Soler *
}

\author{
Manoel Pedro Pimentel
}

Professor titular de Direito Penal na Faculdade de Direito da Universidade de São Paulo.

O ano de 1971 foi particularmente favorável aos estudos de direito penal em São Paulo. A oportunidade foi propíciada pelos debates em torno da reformulação legislativa penal, motivando numerosas reuniões, circulos de conferências, palestras e congressos.

De todos os importantes acontecimentos, repito, todos importantes, destacaram-se três: o Primeiro Encontro dos Tribunais de Alçada, o Primeiro Congresso Estadual do Ministério Público, e a visita que agora nos faz o eminente Professor Sebastín Soler.

Destes três acontecimentos, dois se deveram à iniciativa do dinamico Presidente do Tribunal de Alçada Criminal, Dr. José Luiz Vicente de Azevedo Franceschini, que não regateou esforços para realizá-los, contando sempre com a colaboração cle outras entidades oficiais e particulares. Fica São Paulo a dever inestimáveis serviços a esse notável jurista, que tão sábia e diligentemente conduziu os destinos do Tribunal de Alçada Criminal, no biênio de sua profícua gestão.

Tenho para mim que não houve épocas precedentes tão

* Saudação ao eminente jurista e professor Dr. SEbastian Soler, proferida a 15 de dezembro de 1971, no plenário do Egrégio Tribunal de Alçada Criminal do Estado de São Paulo. 
auspiciosas nos anais da ciência penal, pois neste mesmo ano a reforma universitária instituíu os Cursos de Pós-Graduação na Faculdade de Direito da Universidade de São Paulo, ensejando o início de altos estudos que produzirão, em breve, os frutos esperados.

Por designação especial do Exmo. Sr. Presidente deste Tribunal, cabe-me a honrosa tarefa de saudar e apresentar o conferencista, eminente Professor Sebastián Soler, em nome do próprio Tribunal e das entidades co-promotoras, Comissão de Ciências Humanas do Conselho Estadual de Cultura e Associação Paulista dos Magistrados.

Claro está que o ilustre Professor Sebastián Soler dispensaria apresentações no Brasil, pois aqui é conhecido de todos os que lidam com a ciência do direito penal. Desde os bancos acadêmicos seus trabalhos são recomendados, pela justeza da exposição sistemática, pela clareza dos textos e pelo rigor científico com que foram escritos.

Cumpro a missão, no entanto, pelo prazer de discorrer a respeito da sua vida e da sua obra, e honrado sobremaneira, seu admirador profundo que sou, pelo privilégio de saudá-lo.

"E merecido fazer elogios de Sebastián Soler"

"Talvez não haja penalista que os tenha recebido maiores da minha pena"

"Recordemos, também, que a cultura filosófica de Soler é pouco comum"

Estas palavras não são minhas. Provieram de um dos mais profundos conhecedores do direito penal na América Latina: Luís Jimenez DE AsúA. Bastaria isto para glorificar qualquer penalista, conhecido o rigor crítico com que Asúa delineava suas apreciações.

Sebastián Soler foi aluno de Asúa em Córdoba, na Faculdade de Ciências Jurídicas e Sociais, onde colou gráu 
em 1924, e para onde voltou como professor de direito penal, catedrático convidado, em 1941, no mesmo ano que a sua monumental obra Derecho Penal Argentino obtinha o segundo prêmio concedido pela "Comissão Nacional de Cultura" da Argentina.

Este livro, fruto de cuidadosa elaboração e resultado de sete anos de meditação, deu ao Mestre a oportunidade de expor, sistematicamente, primeiro a Parte Geral, em dois tomos, e depois a Parte Especial em outros três volumes.

Denominou este trabalho, modestamente, de Direito Penal Argentino, quando na realidade é um verdadeiro tratado e mereceria mais de acordo com a sua importancia.

Conta-nos Asúa, na mesma passagem do volume 6, da serie El Criminalista, quando elogiou o Mestre Soler, que este lhe dissera certa vez que preferiu dar ao seu trabalho nome mais modesto, porque seguira a orientação do autor germânico, RoBerto von HIPPEL, que intitulára sua obra, vasada em três alentados volumes, de Deutsches Strafrecht (Direito Penal Alemão), ao invés de Lehrbuch (Tratado)

Consigne-se, em favor do autor, a extraordinária modéstia, pois o próprio Asúa não se recusou a dizer: "Para mim se trata de um livro magnífico, que demonstra a maturidade do talento de seu autor" E observa, em seguida: "Ser penetrante é a característica distintiva do talento de Soler".

Coloque-se em relevo o fato de ser o eminente Professor Sebastián Soler um expoente da cultura jurídica argentina, que pode orgulhar-se de contar com penalistas do porte de Rodolfo Rivarola e Luiz Maria Drago, fundadores, com o Dr. Francisco Ramos Mejía, da Sociedade de Antropologia Jurídica, e que escreveram o estudo a respeito de Los hombres de presa, trabalho conhecido no mundo inteiro como um dos exemplos mais típicos da literatura positivista; ou da elevação de Juan P Ramos, Eusebio GómEz, Eduar- 
do Coll, Juan Silva Riestra, Alfredo Molinario, Carlos Fontán Balestra, Ricardo C. Nunes, Jesus H. Porto e Enrique R. Aftalión, para citar apenas os mais importantes.

O trabalho do Professor Sebastián Soler pode, sem dúvida alguma, ser considerado como uma das construções rigorosamente científicas do direito penal, hombreando em importância, quanto à sistemática, à obra de Binding, aos trabalhos de Beling, ao Tratatto de Manzini e ao fulgurante livro de Delitala Il fatto nella teoria generale del reato, sem embargo das críticas que lhe foram dirigidas por Carlos Cossio e Enrique R. Aftalión.

Em 1943 foi convidado pela Direção de Relações Culturais, do Departamento de Estado dos Estados Unidos a visitar as universidades e centros de estudo e de aplicações práticas, no setor da sua especialidade. Isto se deveu ao seu renome internacional, pois sua fama já ultrapassara os limites de seu país, onde desde 1932 dirigira os presídios de Córdoba, distinguindo-se como criminalista.

Descortinando amplo panorama, elaborou, em colaboração com Vélez Mariconde, o Código de Procedimientos en lo Criminal para a Província de Córdoba.

Espírito independente e caráter reto, em 1947 solidarizou-se com o reitor da Universidade de Córdoba, engenheiro Rodolfo Martinez, renunciando as cátedras que regia, renúncia que não foi aceita, mas que motivou sua expulsão da Universidade e da Câmara de Apelação Criminal que integrava no Tribunal de Rosário.

Como juíz, suas decisões foram sempre paradigmas, influenciado pelo notável conteúdo jurídico a formação da jurisprudência nacional argentina, merecendo algumas delas comentários até mesmo no estrangeiro.

Em 1955, defendeu o contra-almirante Samuel Toranzo 
Calderón, em um recurso extraordinário perante a Suprema Côrte de Justiça da nação, numa demonstração de coragem, porque este acusado era apontado como o principal responsável pelos acontecimentos revolucionários de 16 de junho daquele ano. Já em 1954 havia enfrentado o governo peronista, defendendo os membros da Suprema Côrte de Justiça de Salta em processo político que lhes fora movido.

Participou de numerosos Congressos na Argentina e no estrangeiro, tendo sido membro da comissão de peritos das Nações Unidas, encarregados dos estudos para a prevenção do delito. Autor, também, de um Anteprojeto de Código Penal, foi designado, em outubro de 1955, Procurador Geral da Nação.

Entre as suas obras, destacando-se somente as principais, figuram: $\mathrm{Fe}$ en el derecho $\mathbf{y}$ otros ensayos, Los valores jurídicos e o Derecho Penal Argentino. Entre muitos artigos que escreveu, relacionamos: Acción $\mathbf{y}$ casualidad, polêmica travada com Asúa, em torno do problema da causalidade;Analisis de la figura delictiva; Causas supralegales de justificación; Cuestiones penales y penitenciarias - La Carcel Modelo de Córdoba; De la culpabilidad en general; Imputabilidad y culpabilidad; Interpretación de la ley penal, o que basta para indicar o alto gráu da sua cultura, espraiando-se por muitos campos do conhecimento, sem se falar nos trabalhos de natureza filosófica, como Positivismo y ecletismo e Presupuestos metódicos de los estudios criminalisticos.

Elaborou, ainda, o anteprojeto do Código Penal da Provincia de Santa Fé.

Este é, senhoras e senhores, o conferencista que iremos, dentro em pouco, ouvir. Todos os seus títulos, sua renomada cátedra, sua experiência como magistrado, advogado e Procurador Geral da Nação argentina; sua bagagem cultural, seu prestígio internacional, tudo isto estará presente aqui, nesta 
memorável noite, quando recepcionamos o eminente Professor Sebastián Soler.

\section{Excelentíssimo Senhor Professor Sebastián Soler:}

Posso dizer que é muito grande a expectativa dos penalistas brasileiros a respeito das conferências que Vossa Excelência proferirá. A interação da Política, strictu sensu, com o Direito penal é um aspecto importantìssimo das relações entre a ciência penal e a Criminologia, a Sociologia criminal, e demais ciências afins.

Conhecemos o pensamento de Vossa Excelência e podemos dizer, com Asúa, que foi Vossa Excelência o primeiro penalista da Argentina que rompeu abertamente com o positivismo, adotando uma concepção de estricto dogmatismo jurídico.

São suas estas palavras, no prólogo da primeira edição do Derecho Penal Argentino, escritas em fevereiro de 1940: "O que nos importa afirmar é que a construção dogmática não deve ser barrocamente confundida com apreciações extra-normativas, com opiniões pessoais, com teorias derrogatórias da lei. Uma coisa é a lei e outra é nossa opinião; quando estas não coincidem, ninguém nos privará de dizer o que pensamos; porém devemos saber distinguir o que é a lei daquilo que é somente o nosso desejo"

Colocava-se Vossa Excelência, após sete anos de madura reflexão, na posição de paladino de um dos ramos da corrente técnico-jurídica, filiando-se ao pensamento de BINDING e especialmente ao de BELING, cuja obra mestra seria mais tarde traduzida para o castelhano, por Vossa Excelência, em primoroso trabalho.

Sabemos todos que a orientação jurídico-filosófica de BELING está mais aproximada do neocriticismo formalista de Stammler do que achegada ao positivismo. E é bastante conhecida a convergência das correntes de pensamento que for- 
maram os vários ramos do movimento técnico-jurídico. Enquanto que na Alemanha tal movimento se processava através dos trabalhos de Kelsen, com a sua Teoria Pura do Direito, e de outra corrente formalista, também neokantiana, conhecida como o neocriticismo da Escola de Marburgo, Stammler construía o seu sistema, derivado da mesma teoria kantiana do conhecimento, tal como concebida na Crítica da Razão Pura.

Daí a reação contra a mescla que o Positivismo introduzira na ciência penal, reduzindo-a a um apêndice da Sociologia Criminal, ou da Antropologia Criminal, enfatizando os valores metajurídicos. E esta reação conduzira os pensadores alemães à posição de defesa do formalismo conceitual, separando do jurídico todo elemento não formal. A dogmática assumiu o primeiro posto, passando a ser centro da atenção o direito positivo e a sua elaboração lógica, nascendo a chamada Begriffsjurisprudenz, ou a Jurisprudência dos conceitos.

Paralelamente, na Itália a mesma reação era sentida. Ao proferir a aula inaugural na Universidade de Sassari, em 15 de janeiro de 1910, Arturo Rocco lançava os fundamentos da corrente técnico-jurídica, com o seu discurso sobre o objeto e o método da ciência penal. Seguidores imediatos dessa corrente de pensamento, Massari e Manzini, para destacar apenas os mais importantes, cerraram fileiras em torno das idéias renovadoras, cujo fulcro estava concentrado em depurar o direito penal de todas as influências filosóficas e sociológicas, elevando a dogmática jurídico-penal à categoria de verdadeira ciência.

E notável, então, a coincidência entre o pensamento exposto por Manzini, em seu Tratatto, fundado nas posições da corrente técnico-jurídica italiana e o de Vossa Excelência, abeberado, nas origens, nos ensinamentos das célebres Normen de Binding e nos esquemas de Beling. Disse Manzini à pág. 4 do seu tratado: "A concepção técnico-jurídica, à qual nos ateremos exclusivamente, considera o direito penal como um 
sistema de preceitos e sanções, que se forma e vive necessariamente no organismo político do Estado, e não fora dele, apesar de que a matéria da sua elaboração jurídica seja fornecida pelos mais diversos campos da atividade individual e social."

Estas afirmações de MANZini se igualam aos dizeres lapidares de Vossa Excelência, quando, no mesmo Prólogo do seu monumental trabalho, afirmou: ". . . entre o maior tratado $\epsilon$ a mais modesta lei penal existe uma diferença qualitativamente insuperável" $\mathrm{Ou}$, então, "A lei é com frequiência mais sábia do que se supõe; porém para entendê-la é preciso estudá-la com ânimo prudente e boa vontade"

Assinala Miguel Reale, no seu esplêndido livro $O$ direito como experiência, às págs. 95 e seguintes, que foram numerosas e importantes as conseqüências do tecnicismo normativo, a que êle denomina, genericamente, "corrente técnico-jurídica". E resume os postulados dessa Escola, com o afirmar que "prevalece a convicção de que a Jurisprudência deve manter-se alheia a qualquer tipo de investigação de caráter axiológico, a fim de não ver comprometida a sua autonomia ou neutralidade científica, por não se perceber que uma coisa é, penso eu, compreender uma realidade social "sob prismas de valor" (o que corresponde ao verbo valorar), isto é, segundo suas objetivas conexões do sentido, e outra coisa é pretender subordinar a realidade social a uma prévia tomada de posição axiológica".

Analisando os exagêros a que foram conduzidos os corifeus da nova corrente de pensamento, especialmente no campo do direito penal, o mesmo autor entendeu bastante relembrar o que essa orientação representou, "inclusive porque, nessa esfera do Direito tão densa de problemática axiológica, mais se fazem notar os exageros neutralistas de autores como ARTUro Rocco, Manzini e Massari." Em nota de rodapé ilustra o seu pensamento, transcrevendo palavras de ManzinI quando sustenta que o direito penal seria "a ciência de normas impe- 
rativas, que nada têm de comum com as leis naturais e sociais, nem se propõe a descrever fatos ou relações, nem a estudar relações de causalidade social"

$\mathrm{E}$, em crítica aguda formulada relativamente às conseqüências decorrentes do pensamento técnico-jurídico, José Maria Stampa Braun, em seu magnífico trabalho Introduccion a la ciencia del derecho penal, destaca: "O formalismo, em troca, transformaria a ciência punitiva em conhecimento adequado à natureza normativa de seu próprio objeto, quer dizer, em verdadeira disciplina jurídica. Seu pecado capital estaria, não obstante, em haver parado aí a especulação jurídico-penal, sem se dar conta do caráter teleológico-valorativo que ao direito penal convém em maior medida do que a nenhum outro"

"O formalismo é, na ciência do direito, uma conseqüência do positivismo jurídico. Tendo-se em conta que este movimento foi o inspirador da tendência técnico-jurídica, não é estranhável que muitos dos militantes nesta incidissem nos exageros trasladando seu cânones. consciente ou inconscientemente, à ciência do direito punitivo"

$\mathrm{E}$, finaliza, "Mediante esta tendência para a objetivação absoluta e imutável dos conceitos elaborados por procedimentos lógico-abstratos, chegou a olvidar-se a finalidade racional e prática das instituições jurídicas, para conservar unicamente seus elementos conceituais, destacados da natureza e da vida. Daí converter-se o dogmatismo em tendência a impor-se como se fôsse uma fé, uma verdade absoluta"

Claro que, a não ser na corrente kelseniana, da Teoria Pura do Direito, cujo único seguidor importante foi Tesar, e que não teve maior aceitação, as demais não conseguiram manter-se na posição rígida inicialmente assumida, por afastarem considerações de ordem sociológicas ou de ordem moral. Nos escritos de muitos autores, confessa-o mais tarde MANZI NI, haverá a aceitação dessa indispensável contribuição das 
demais ciências, embora permaneça a recusa sistemática de sua intromissão no campo da dogmática.

Aliás, o pregão inicial de Rocco consignava os três momentos: dogmática, exegése e crítica. Como penetrantemente observou Asúa, o que também foi feito por De Marsico, os exageros se constituiram em desvios do primeiro comando da corrente técnico-jurídica, que recomendava o equilíbrio nestes três momentos.

E foi por isso mesmo que Asúa, no volume 6 do El Criminalista, analisando o trabalho de Vossa Excelência, observou que "talvez o ardor do noviciado possa ter levado o autor a um exagerado dogmatismo meramente legal, arredando todo o suplalegal, principalmente quanto às justificativas".

Mas, percebe-se na evolução do pensamento de Vossa Excelência, através de alguns trabalhos posteriores, que esse radicalismo inicial foi cedendo, e que Vosșa Excelência se manteve fiel ao ensinamento originário de Rocco, pois não se descuidou de fazer a crítica necessária, especialmente quando tratou de acolher princípios dogmáticos imperantes em legislações alienígenas.

Ao traduzir a obra fundamental de Beling, Vossa Excelência fêz consignar, no Prefácio do tradutor: "A teoria do delinqüente nato pode ser universal; porém as construções técnicas sobre o Tatbestand não têm a mesma pretensão. Sua validade está geralmente condicionada a um sistema; somente um exame sempre atento às particularidades do direito próprio pode validamente conduzir-nos à aceitação ou à recusa"

Esta consciência e esta atenção, estavam também presentes quando Vossa Excelência rejeitou as excludentes supralegais, porque, assinalava Vossa Excelência, os alemães tiveram necessidade de recorrer a esse expediente, dada a imperfeição do seu direito positivo, que omitira necessárias hipóteses de justificativas. Entretanto, em um sistema de direito positivo que 
previsse todas as circunstâncias em que houvesse necessidade de justificar legalmente o comportamento do agente, não haveria espaço para deixar largo o arbítrio judicial, descozido de lei, ao ponto de enunciar-se uma genérica teoria da não exigibilidade de outra conduta.

Muito tempo decorreu desde a primeira edição da sua obra fundamental, Derecho Penal Argentino. A evolução do pensamento, como em tudo, se fez também no campo do direito penal. A Begriffsiurisprudenz foi sucedida pela Interessenjurisprudenz que, por sua vez, cedeu passo à Turisorudência. dos valores. Windelband e Rickert, com suas doutrinas teleolóogicas. viriam influenciar. pelas novas posições metodológicas, todas as ciências iurídicas. Carneluttri, na Itália, fez uma tentativa de "civilizar" o direito Denal. Reagem MagGioRE e ANTOLIsei contra a atomização do conceito do delito. A corrente do Idealismo Atualístico, de Ugo SpIRIro, saída das posicões filosóficas de Crocce e Gentile, e o Néo-humanismo de LANZA dão lugar à doutrina de BetTiol que se firma na consideração dos valores. Na França. MArc Angel lança os fundamentos da Nova Defesa Social. ao mesmo tempo aue idéias semelhantes são expostas na Itália por Fillippo Grammática. No Brasil, ainda são imprecisos os contôrnos do pensamento jurídico-penal. A corrente técnico-jurídica goza da preferência dos tratadistas, vivo que está, ainda, o memorável ensinamento de ARTURo Rocco, depurada porém dos exageros aludidos. Filosoficamente, é importante constatar a presença do pensamento de Miguel Reale, e a moderna concepção do direito como experiência, resultando na afirmação de que o objeto da Ciência Jurídica "deve ser antes visto como o complexo das normas em função das situações normadas, ou seja, como a experiência jurídica mesma enquanto se torna plenamente objetiva como ordenamento jurídico."

No entanto, o Código Penal já convertido em lei, e aguardando vigência, parece não haver colhido nenhum benefício de todas as modificações havidas no mundo nestes últimos 
trinta anos. De índole positivista, rejeitou a medida de segurança aplicável aos imputáveis. Filiado ao pensamento técni$\mathrm{co}$, acolheu a não exigibilidade de outra conduta, como causa de justificativa supralegal. Contraditório e eclético, o legislador penal brasileiro, de 1969, propôs um sistema punitivo inexequível, nas condições da nossa realidade, tímido no aceitar os ensinamentos da Universidade, débil no acolher as recomendações dos Congressos científicos, servil no copiar a maioria dos institutos do Código penal atual, cópia, por sua vez, do código italiano, elaborado sob a égide do fascismo, sem atender aos reclamos da experiência jurisprudencial.

Daí a expectativa com que aguardamos as conferências de Vossa Excelência, principalmente as duas que tratarão da interação da Política com o Direito penal. Entendemos que Vossa Excelência vai colocar o problema da Jurisprudência frente à Ciência Política (strictu sensu) e esperamos que o seja para realçar a importância dessa interação. Justifica-se esta expectativa ansiosa, porque desejamos ver confirmada a posição já denunciada em alguns trabalhos de Vossa Excelência, no sentido de admitir a contribuição de outros ramos do conhecimento humano na interpretação do direito penal positivo, especialmente dentro da linha de pensamento que valoriza o momento pré-jurídico, em que se elaboram as leis, e o momento da aplicação do direito, porque, como disse com muito acerto Miguel Reale, "Direito e Estado são realidades que se dialetizam segundo um nexo de complementariedade, corresponde, em última análise, a que liga o licitum ao debere"

A palavra de Vossa Excelência será ouvida por todos com o respeito e a admiração condizentes com a magestade do seu saber e a autoridade da sua experiência. 